\title{
TAKING CARE OF THE PLANET: DESIGNING WITH BIOPOLYMERS
}

\author{
Luis PATIÑO and Lumy NOUGUEZ \\ Universidad EAFIT, Medellín, Colombia
}

\begin{abstract}
Educating designers and engineers about more sustainable design practices has been a challenge. The courses included in Product Design Engineering need to explain the fundamentals of materials science, their applications in design, and take into consideration the recent achievements in this field. New materials and technologies are evolving rapidly; however, classroom teaching is becoming insufficient in catching up on these developments. It is necessary to explore alternative materials, such as biopolymers, to replace synthetic materials and composites by reducing the spectrum of material family and find new and better solutions for design with an ecological conscience. Hence, it is crucial to engage the third-year undergraduate students in Medellin, Colombia, to combat the $21^{\text {st }}$ Century challenges of Sustainable Development Goals (SDG), and encourage them to work creatively with new materials that reduce the environmental impact.

This paper presents a material design course "Designing with biopolymers", which focuses on selflearning while working on a project. It is expected to close the gap between the new materials and the current educational practices. The course is divided into two stages. In the first stage, the students design and fabricate organic materials with which they explore the possible variations using some technologies. In the second stage, they apply various design methodologies on these materials and find possible applications that match their properties. As a result, they learn how biopolymers can take innovation to the next level in the future, and how they can achieve sustainability.
\end{abstract}

Keywords: Sustainability, biopolymers, design, self-learning

\section{INTRODUCTION}

Designing with sustainability as a "noun" [1] constitutes the material revolution of the $21^{\text {st }}$ Century. Global warming, the carbon footprint caused by material processing industries, and the fast invasion of microplastics due to the tremendous increase in the cultural consumption [2] are some of the problems facing the discipline of design. We are obliged to educate the product design engineers (PDE) by introducing them to alternative materials that have a lower carbon footprint and by creating awareness for "essential care" [1] when using these materials in products or services to integrate them into society. International companies such as Adidas and Nike are currently betting on the environment policy statement and are promoting their products made of recycled plastics, which are already commercially available. H\&M receives waste garments for recycling as part of a purchase incentive, and giants of design such as IKEA markets products (e.g. Odger Chair; 30\% wood, 55\% recycled plastic, or the Kungsbacka kitchen; 1000 PET bottles reused in one kitchen) as sustainable strategies. These efforts seem good but are insufficient for 2020 - when global warming is already a concern [2]. The initiative named "Parley for the oceans", with the participation of G-star and Adidas, conveys a vital message: "to take care of our oceans" and educates people outside classrooms under such events as the "Ocean Climate life 2015", World ocean week 2018 and "Parley talks: Nasa JPL". Unfortunately, this sensitisation reaches Latin American countries years after, and most of the people believe that there is no crisis, and hence, they tend to continue the exploitation of natural resources.

The efforts of several companies, engineers and designers are included in the book, "Radical Matter"[3], wherein they propose materials for a sustainable future as a way to stop producing waste and to stop treating the earth as if its resources are unlimited. This paper calls for a wiser approach to resolve the recycling problem and presents ideas and knowledge that could lead to a better future - or at least, a more bearable one. However, some of these examples sound like science fiction or unlikely practices that could be achieved by PDE students. 
Only a few universities in Colombia include the "Ecoaudit programme" by CES Edu pack in their bachelor and postgraduate courses. This software enables a quick and early design overview of the environmental impact of products by considering different phases of the products' life cycle in terms of energy consumption and carbon footprint [4]. Some educational resources such as papers, case studies and lectures help students to analyse this subject matter. Additionally, material libraries such as Material ConneXion [5] are increasingly striving to disseminate knowledge on materials that come from natural or hybrid sources as an alternative to synthetic plastics. However, initiatives to teach about the manufacturing of sustainable materials at a local level are limited, and the libraries display samples that come from Asia, America or Europe, but not from Latin America.

This paper presents an educational strategy that aims at rethinking the pedagogy of materials in terms of sustainability as the core of this course, linking it with a design project and making sustainability a "noun" and not an "adjective" for undergraduate students [1]. The course named Special project: Designing with biopolymers was created for the intermediate cycle of the PDE programme based on the book The Philosophy of Caring by Leonardo Boff. First, they would need to design biopolymers with simple and natural ingredients, thus exploring innovative components and mixtures. Second, the materials would have to be transformed with available technologies to achieve certain properties. Finally, the apprentice would design products using these materials, adjusting to their constraints and taking advantage of their possibilities in new products. Thus, the student, as the main actor in the learning process, would carry out the two-step design process: (1) designing new biopolymers in an exploratory stage, and (2) understanding the nature of the materials and how these could reduce energy consumption during their production, besides increasing their recycling possibilities in order to have a reduced environmental impact.

\section{COURSE DESIGN: NEW MODEL}

This course was offered to the students of the PDE programme, from fifth to ninth semester as a "Special Project", as an experiment where biopolymers were the centre of the design processes. According to Andrea Merloni in his book Material driven design, "materials and sustainability are thus essential for starting innovation processes, both in terms of ergonomic, physical and processability aspects, and in terms of recycling and reusing materials at the end of the life product" [6].

This course was 17 weeks long and was divided into two stages: material and design exploration, (Stage 1) and exploring product design concepts with the new material (Stage 2) (see Figure 1). These stages are explained below.

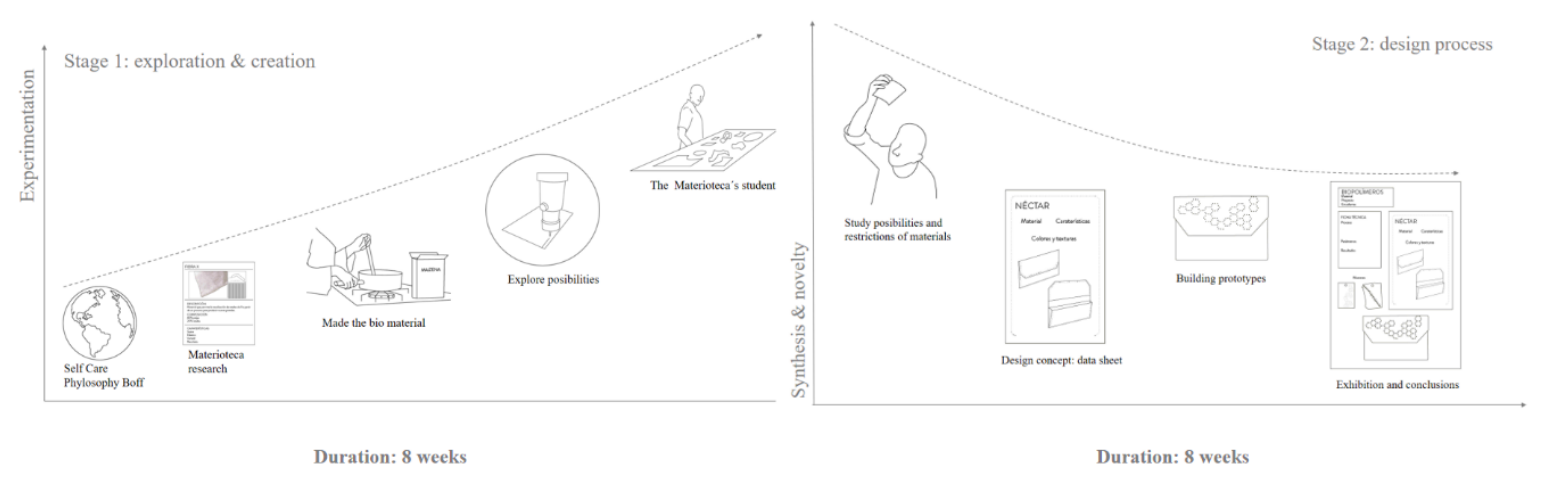

Figure 1. Overall course design

\subsection{Stage 1: Awareness, creation and exploration}

The purpose of the project was to create awareness for taking care of the planet through lessons from the book Essential care by Leonardo Boof, where he explains the concept of sustainability as an expression to rethink the life, nature, and earth systems. This summarises the philosophy for the wellbeing in some principles that are based on not consuming more of what the system can support, avoiding waste production that cannot be absorbed safely, reusing and recycling and practicing a more frugal living to avoid shortage in the future. Regarding this, the course explains the importance and 
advantages of using biopolymers to the field of design, and how some designers and companies around the world are already devising strategies that validate this philosophy of sustainability. To go in depth in the state of the art, the students conducted a self-learning activity where they researched on a biopolymer from the Material library of the Material ConneXion database (available at EAFIT campus). They summarised all the attributes of each chosen material as a datasheet, recording information such as the description, composition, sensorial characteristics, perceptions and possible applications (Figure 2). The purpose of this exercise was to understand the properties of the biopolymer to prepare them for the upcoming materials in this project.
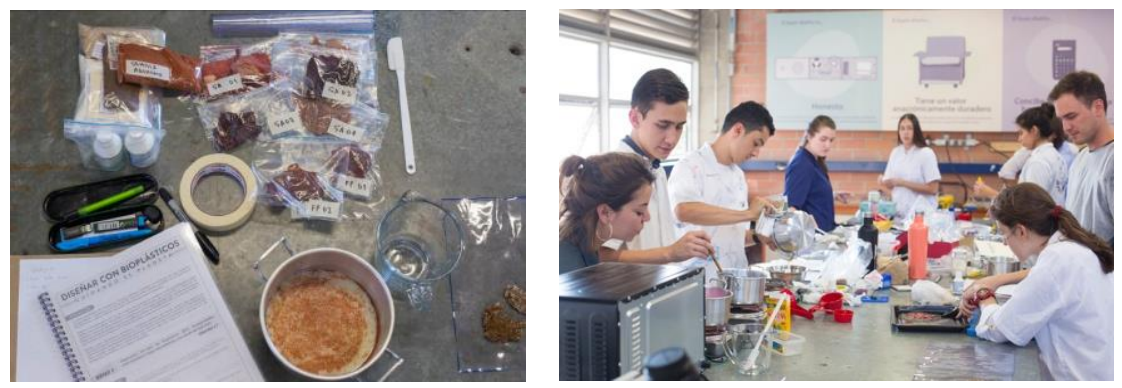

Figure 2. Datasheet from Materioteca research

From the second week of the course, the students conducted experiments and developed biopolymers made of natural and common substances such as corn starch, potato starch, agar agar, avocados seeds, psyllium husk and casein. They obtained physical samples and made changes to the recipes to improve properties such as humidity resistance, stiffness, ductility, malleability and appearance. The data related to the fabricated material, such as the amount of the constituents, variations and some parameters of the process in every sample were recorded. Similarly, in some cases, the students took into consideration recommendations pertaining to preservatives, natural adhesives, vegetable pigments, waterproofing materials, among others. Additionally, they explored some options for improving the properties of the materials with natural fillers, such as coffee grounds, activated carbon, cotton fibres, metallic mesh and eggshells.
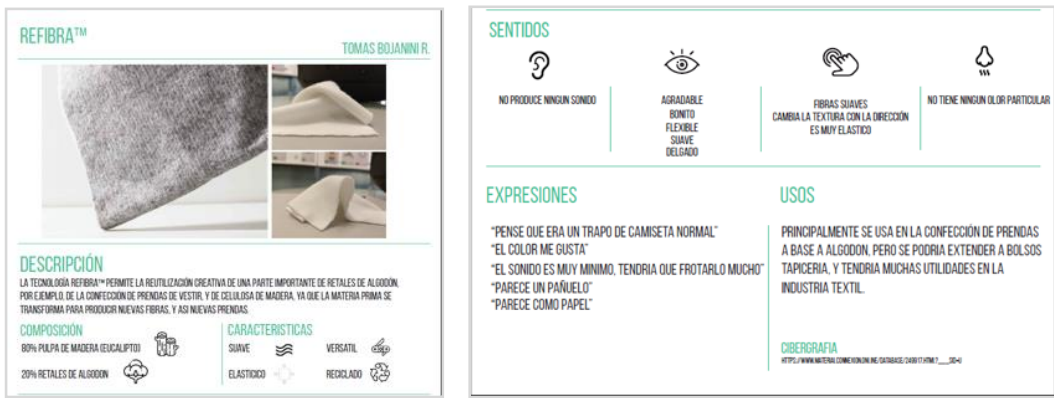

Figure 3. Designing biopolymers during workshop for four weeks

Finally, throughout this stage, the biopolymers were processed in the university workshops via various methods. Such processes include extrusion, heat pressing, thermoforming, laser cutting, saw cutting, sewing technology and addition of reinforcement using metal mesh, cotton and wood moulds to retain the desired shape. These processes enhanced the appearance, conformability and mechanical or chemical strength of the materials. Thereupon, the characteristics of the materials were investigated, after which all the possibilities and constraints were summarised in a datasheet to determine their possible applications. Figure 3 shows some examples of the datasheets. 

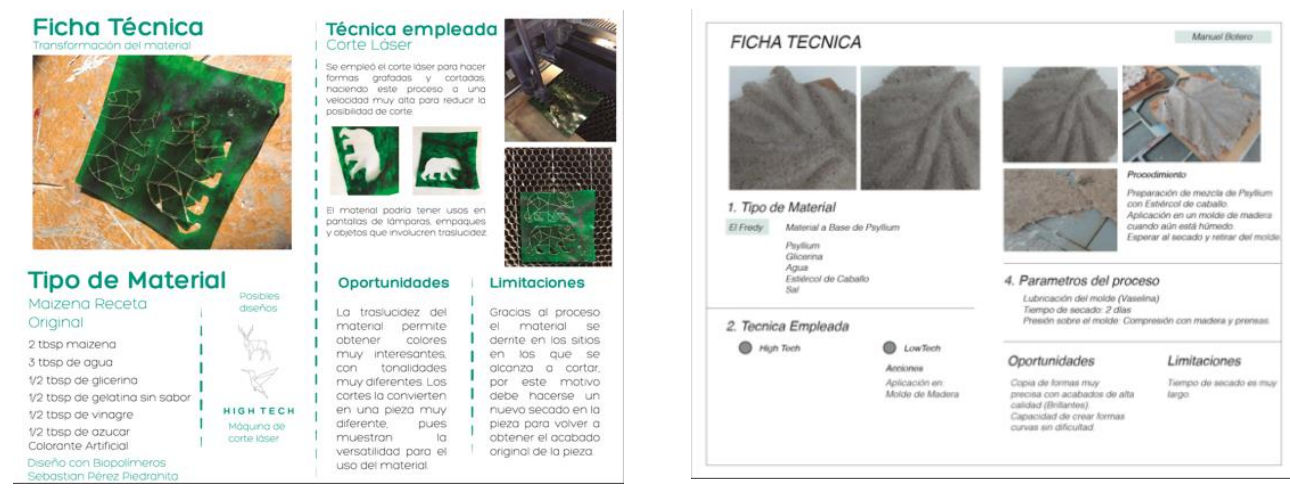

Figure 4. Data sheet by processes of biopolymers with some variations

Based on the obtained experimental results, the students discussed their results in group sessions, and each of them chose the three most representative biopolymers according to their best technical and sensorial attributes (see Figure 1). The apprentices created their own "Materioteca" and chose the ones most representative; thereupon, they analysed the qualitative characteristics of the materials, such as tear resistance, waterproofing, heat resistance, ductility, biodegradability, ageing stability and production feasibility. In addition, some aesthetic attributes such as texture, smell, sound and optical properties were evaluated. With these results, the students started Stage 2 with the design concept, as described below.
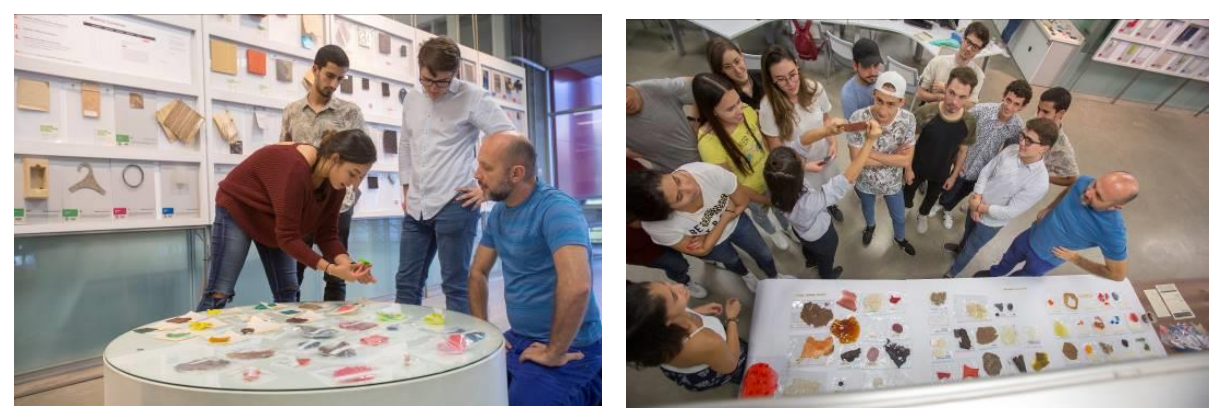

Figure 5. Exhibition of the own Materioteca

\subsection{Stage 2: Design process with biopolymers}

In Stage 1, students encountered challenges in the design process, such as selecting the appropriate product category to work with according to the material, making a functional model with the new materials that allow them to derive conclusions and circulating the results within the academic community (see Figure 1). During the conceptualisation, the constraints and possibilities associated with the materials were studied to determine the possible applications in terms of the final products that would respond to a necessity. The categories included fashion accessories, jewellery, packaging, lighting systems, green walls and sound systems.

After the material selection, the students proposed ideas through drawings, sketches and soft models to develop the design concept. They defined details and tested the behaviour of the materials. Finally, they defined the details of the products by making a final prototype in a scale of 1:1 and summarised all the information in a printed poster, along with the main data sheets, for the purpose of evaluating and exhibiting the final results.

\section{RESULTS \& DISCUSSIONS}

The materials developed in Stage 1 were transformed experimentally with new mixtures, varying ratios and constituents, and using the different available manufacturing processes to exploring possibilities for new products. The results are illustrated in Table 1. 
Table 1. Biopolymers, properties, manufacturing processes and applications

\begin{tabular}{|c|c|c|c|c|}
\hline $\begin{array}{l}\text { Biopolymers } \\
\text { base }\end{array}$ & Properties & $\begin{array}{l}\text { Improvements in } \\
\text { material } \\
\text { properties }\end{array}$ & $\begin{array}{l}\text { Applied } \\
\text { technologies }\end{array}$ & Products \\
\hline \multirow{3}{*}{$\begin{array}{l}\text { Psyllium } \\
\text { husk }\end{array}$} & \multirow{3}{*}{$\begin{array}{l}\text { Flexible but } \\
\text { fragile }\end{array}$} & $\begin{array}{l}\text { Better resistance to } \\
\text { tearing with metal } \\
\text { mesh layering and } \\
\text { colourants } \\
\text { Better } \\
\text { processability with } \\
\text { activated carbon }\end{array}$ & $\begin{array}{l}\text { Laser cutting } \\
\text { Shaping with wood } \\
\text { moulds. }\end{array}$ & wall green \\
\hline & & $\begin{array}{l}\text { decrease in the } \\
\text { drying time when } \\
\text { reinforced with } \\
\text { cotton fibre }\end{array}$ & $\begin{array}{l}\text { Laser cutting and } \\
\text { sewing }\end{array}$ & wallet \\
\hline & & $\begin{array}{l}\text { More rigidity and } \\
\text { new appearance } \\
\text { with paper and } \\
\text { horse manure }\end{array}$ & $\begin{array}{l}\text { Laser cutting and } \\
\text { pressing }\end{array}$ & Office system \\
\hline $\begin{array}{l}\text { Casein from } \\
\text { expired milk }\end{array}$ & Fragile & $\begin{array}{l}\text { Better impact and } \\
\text { heat resistance by } \\
\text { adding cinnamon }\end{array}$ & $\begin{array}{l}\text { Pressing in plaster } \\
\text { mould (less humidity } \\
\text { and better } \\
\text { dimensional stability } \\
\text { of the final piece) }\end{array}$ & planter \\
\hline $\begin{array}{l}\text { Avocado } \\
\text { seeds }\end{array}$ & Flexible & $\begin{array}{l}\text { Improved } \\
\text { conformity due to } \\
\text { reinforcement with } \\
\text { cotton fabric }\end{array}$ & $\begin{array}{l}\text { Fibre impregnation } \\
\text { and drying in oven. } \\
\text { Glycerine hydration }\end{array}$ & vest \\
\hline $\begin{array}{l}\text { Manioc } \\
\text { starch and } \\
\text { Glycerine }\end{array}$ & $\begin{array}{l}\text { Ease of } \\
\text { moulding, } \\
\text { transparency }\end{array}$ & $\begin{array}{l}\text { Water resistance } \\
\text { improved with bee } \\
\text { wax. } \\
\text { Better optical } \\
\text { properties with } \\
\text { coffee grounds }\end{array}$ & $\begin{array}{l}\text { Extrusion } \\
\text { Pressing }\end{array}$ & $\begin{array}{l}\text { Wall lighting } \\
\text { Fashion } \\
\text { accessories }\end{array}$ \\
\hline Corn starch & $\begin{array}{l}\text { Ease of } \\
\text { moulding }\end{array}$ & $\begin{array}{l}\text { Edible with berries, } \\
\text { sugar and } \\
\text { unflavoured } \\
\text { gelatine }\end{array}$ & Moulding & Sugar packaging \\
\hline
\end{tabular}

The most remarkable discoveries are listed as follows:

- Ordinary materials available in grocery stores or pharmacies, such as psyllium, starch, glycerine and milk (casein) as well as organic wastes such as coffee ground, avocado seeds, expired milk and horse manure were valuable materials in this project. The psyllium husk enabled more transformations with other constituents and processes.

- Water resistance has always been a challenge in biopolymers. In their experiments, improvement 
in water resistance was achieved using bee wax, and the humidity absorption was improved by using cotton as a reinforced fibre or by processing the material by using a plaster mould.

- Cotton, paper and metal mesh are good reinforcement materials for future applications.

- Optical properties were improved using natural pigments such as curcuma, berries and coffee ground; some achieved transparency and translucent effects that are resourceful for fashion accessories and lighting systems.

- Laser cutting allowed accurate fabrication of shapes, and the heat pressing helped to maintain dimensional stability.

- It is more difficult to manufacture and control biopolymers with bigger dimensions. Processing time, dimension and shape stability, drying time and assembly methods with other materials get more complex as the size of the biopolymer increases.

- The materials based on ground and fermented avocado seeds, and horse manure mixed with psyllium were considered innovative, and the students were able to get the best out of them to create new products.

- Most of the manufactured products were created from biopolymer sheets because it is difficult to mould these materials into complex shapes. The moulding processes depend on the nature of the material and ageing stability.

\section{CONCLUSIONS}

The self-learning method enabled students to research on how to make biopolymers on their own and apprised them on developments in this area. In addition, they discovered the advantages of using biopolymers, which challenged them to learn through creative thinking, thus leading them to design innovative products. However, they explored only the concepts; therefore, the next challenge will be the laboratory analyses of the materials.

Furthermore, the constraints associated with the biopolymers encouraged the creativity of the apprentice as they were charged with the responsibility of improving the properties of the biopolymers in order to adjust them to suit the project requirements and to take advantage of the materials' potential: "The forms follow the material".

The design process employed here varied from a divergent stage (creating the material) to a convergent stage (designing a product with certain material). This can be a novel learning experience for an IDP because this process allows approaching materiality in different ways and prepares the students to design more sustainable products. This is a good opportunity to face the new developments in materials and to update the curriculum to incorporate the new challenges.

The designers might discover opportunities for start-ups based on their discoveries (nowadays, the avocado seed research from this project is in progress) due to the promising properties of the developed materials. Research on new biopolymers can lead to new innovations.

In this project, biopolymers were evaluated exclusively from a qualitative point of view and could serve as the basis for future evaluation of biopolymers, which may include the evaluation of their mechanical, physical and chemical properties, thus guaranteeing their performance in new products.

\section{REFERENCES}

[1] Boff, L. El cuidado necesario, 2012 (Trotta).

[2] Wallace D. El planeta inhóspito, 2019. (Debate).

[3] Franklin, K, and Till, C. Radical Matter. rethinking materials for a sustainable future, 2018. (Thames and Hudson).

[4] Ahsby, M. Teaching Engineering Materials: CES EduPack, 2012. (Granta).

[5] Sandow. Material Connexion. A Sandow company. Available: https://www.materialconnexion.online/database/customer/account/. [Accessed on 2020, 22 February], (2020).

[6] Indesit, company. Materials driven design. Il progetto Eldomat. 2012. (Dodici edizione). 